\title{
COMPARISONS OF BUCKLING CAPACITY CURVES OF PRESSURIZED SPHERES WITH EDR PROVISIONS AND EXPERIMENTAL RESULTS
}

\author{
Paweł BŁAŻEJEWSKI ${ }^{1}$, Jakub MARCINOWSKI ${ }^{2}$ \\ Institute of Building Engineering, \\ University of Zielona Gora, Zielona Góra, Poland
}

\begin{abstract}
Existing provisions leading to the assessment of the buckling resistance of pressurised spherical shells were published in the European Design Recommendations (EDR) [1]. This book comprises rules which refer to the stability of steel shells of different shapes. In the first step of the general procedure they require calculation of two reference quantities: the elastic critical buckling reference $p_{\mathrm{Rcr}}$ and the plastic reference resistance $p_{\text {Rpl. }}$ These quantities should be determined in the linear buckling analysis (LBA) and in the materially nonlinear analysis (MNA) respectively. Only in the case of spherical shells the existing procedure has exceptional character. It is based on the geometrically nonlinear analysis (GNA) and on the geometrically and materially nonlinear analysis (GMNA), respectively. From this reason, in this particular case there was a need to change the existing approach. The new procedure was presented in the work of Błażejewski \& Marcinowski in 2016 (comp. [2]). All steps of the procedure leading to the assessment of buckling resistance of pressurized steel, spherical shells were presented in this work. The elaborated procedure is consistent with provisions of Eurocode EN1993-1-6 (comp. [3]) and with recommendations inserted in Europeans Design Recommendations [1]. The proposed capacity curves were compared with existing proposal published in [1] for three different fabrication quality classes predicted in [3]. In this work also comparisons of author's proposals with experimental results obtained by other authors were presented.
\end{abstract}

\footnotetext{
${ }^{1}$ Corresponding author: University of Zielona Gora, Institute of Building Engineering, Szafrana st 1, 65-516 Zielona Góra, Poland, e-mail: p.blazejewski@ib.uz.zgora.pl, tel.+48683282322
} 
Keywords: steel spherical shells, buckling resistance, capacity curve, numerical approach, FEM.

\section{INTRODUCTION}

Steel, spherical shells subjected to the action of external pressure $p$ are usually very slender and internal forces which are generated within their domain are compressive. For this reason they are exposed to local or global buckling, probably the most important reasons for failures of such shells. An accurate assessment of the buckling resistance, as the maximum pressure $p$ which can be safely sustained, is very important from the engineering point of view. The buckling limit state (LS3 according to EN 1993-1-6) is usually the decisive criterion among all design criteria.

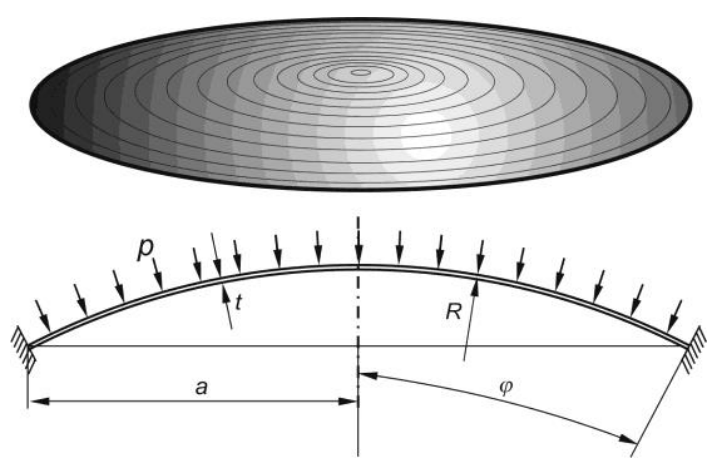

Fig. 1. Pressurised, spherical shell

Existing designing provisions define precisely procedures leading to the buckling resistance assessment of steel shells (cf. EN 1993-1-6). The approach based on the MNA analysis and LBA analysis [11] is a commonly accepted approach as far as the plastic reference resistance $p_{\text {Rpl }}$ and elastic critical buckling reference $p_{\text {Rcr }}$ are concerned. These are two reference quantities on the basis of which buckling capacity curves for particular cases of shells are created. EDR 5th includes provisions which refer to several cases of shells exposed to buckling. In the existing chapter dedicated to spherical shells the different approach was adopted. Reference quantities of the whole procedure $p_{\text {Rcr }}$ and $p_{\text {Rpl }}$ are determined on the basis of the GNA (geometrically nonlinear analysis) and the GMNA (geometrically and materially nonlinear analysis) respectively and it is a single exception in these recommendations.

In this paper an alternative approach was presented, the approach consistent with the general approach recommended in EN 1993-1-6 and in EDR 5th. All steps of the proposed approach were presented in [2]. All parameters defining capacity curves were obtained as a result of many numerical analyses carried out for 
spherical shells of different geometry and different material parameters. Spherical caps of semi-angles $\varphi=10^{\circ}, 20^{\circ}, 30^{\circ}, 45^{\circ}, 60^{\circ}, 90^{\circ}$ and of following $R / t$ ratios: $R / t$ $=300,400,500,600,750,1000$ were considered. Seven different imperfection modes were taken into account and three fabrication quality classes were considered. Only one case of boundary condition was taken into account: the fully clamped basic circle of considered caps (see Figure 1).

In this work also comparison of the proposed approach with experimental results of other authors was presented and this comparison is a valuable verification test for buckling capacity curves elaborated by authors.

\section{ELASTIC CRITICAL BUCKLING RESISTANCE AND PLASTIC REFERENCE RESISTANCE}

The elastic critical buckling resistance $p_{\mathrm{Rcr}}$ and the plastic reference resistance $p_{\mathrm{Rpl}}$ are principal quantities required in the buckling resistance assessment procedure. An attempt of derivation of the simple formulae on $p_{\mathrm{Rcr}}$ and $p_{\mathrm{Rpl}}$ was undertaken by Authors earlier [4].

To find this formulae many numerical analyses (LBA - the linear buckling analysis in reference to $p_{\mathrm{Rcr}}$ and MNA - the materially nonlinear analysis in a case of $\left.p_{\mathrm{Rpl}}\right)$ were carried out for a huge range of $R / t$ ratios and for a great diversity of semiangles $\varphi$ defining the rise of spherical shells. Details of this stage of the research were presented in Błażejewski and Marcinowski [4]. As a result the following formulae were obtained:

$$
\begin{aligned}
& p_{\mathrm{Rcr}(\mathrm{LBA})}=1.303 E\left(\frac{t}{R}\right)^{2} \\
& p_{\mathrm{Rpl}_{(\mathrm{MNA})}}=1.986 f_{y k} \frac{t}{R}
\end{aligned}
$$

in which $E$ - Young's modulus, $f_{\mathrm{yk}}$ - characteristic value of the yield stress, both expressed in $[\mathrm{MPa}]$.

Formulae (1) and (2) differ slightly from formulae presented in Błażejewski and Marcinowski [4]. They are derived on the basis of the same results of numerical analyses but in the proposed amendments the more accurate best-fit procedures were implemented.

The determination of the citical pressure $p_{\text {Rcr }}$ and the plastic reference pressure $p_{\mathrm{Rpl}}$ according to EDR [1] takes place in a very similar way. These quantities can be determined from the following formulae: 


$$
\begin{aligned}
& p_{\mathrm{Rcr}(\mathrm{GNA})}=0,97 E\left(\frac{t}{R}\right)^{2} \\
& p_{\mathrm{Rpl}_{(\mathrm{GMNA})}}=1,80 f_{y k} \frac{t}{R}
\end{aligned}
$$

Coefficients used in these formulae are different than their counterparts in formulae (1) and (2) and it follows from different approach used in both cases.

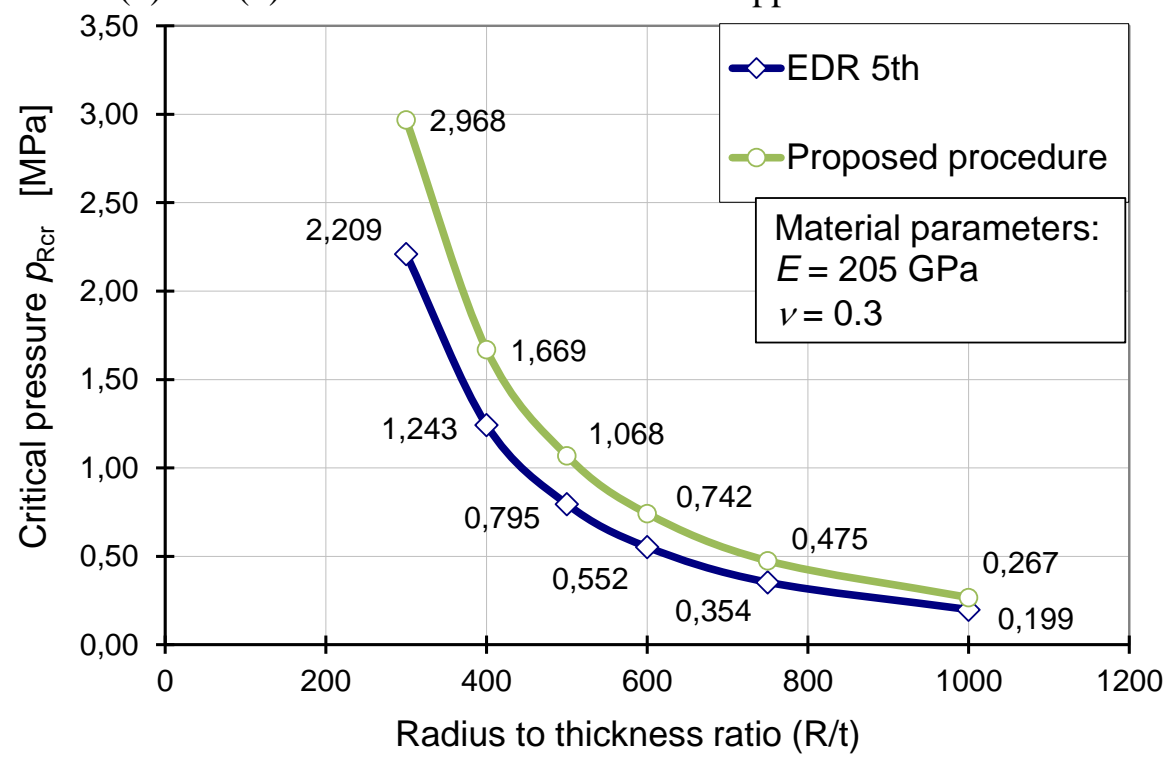

Fig. 2. Critical pressure $p_{\text {Rer }}$ according to the proposed procedure and due to EDR $5^{\text {th }}$ provisions

The summary of curves presenting the critical pressure due to formulae (1) and (3) respectively are shown in Figure 2 as a function of $R / t$ ratio. Differences between both proposals are easily visible.

Having both defined above reference quantities, namely $p_{\text {Rcr }}$ and $p_{\text {Rpl }}$, one can calculate the dimensionless relative slenderness defined in the standard way

$$
\lambda=\sqrt{p_{\mathrm{Rpl}_{(\mathrm{MNA})}} / p_{\mathrm{Rcr}(\mathrm{LBA})}}
$$

and resspectively:

$$
\lambda=\sqrt{p_{\mathrm{Rpl}_{(\mathrm{GMNA})}} / p_{\mathrm{Rcr}(\mathrm{GNA})}}
$$


The calculation of relative slenderness is a very easy task due to the fact that all quantities appearing under the square root symbols are described by formulae.

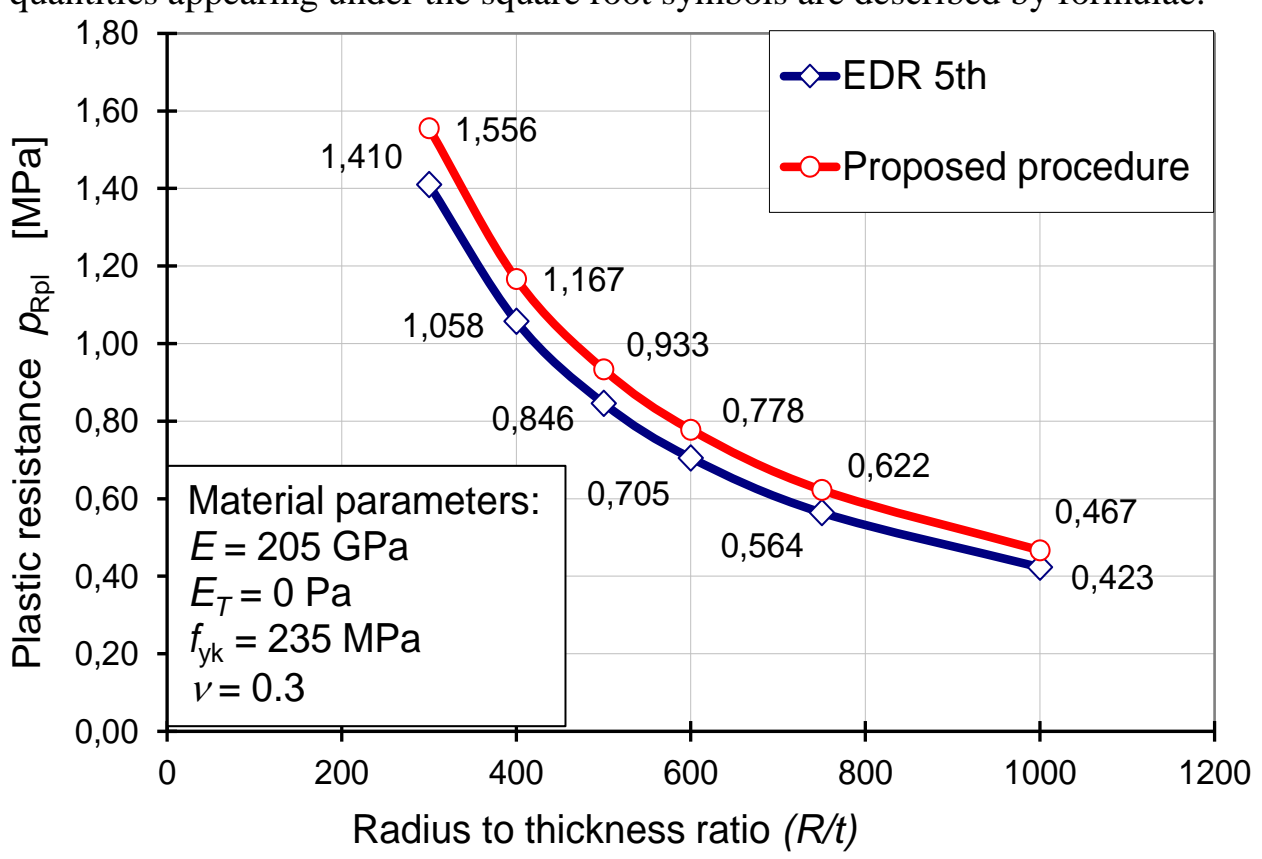

Fig. 3. Plastic resistance $p_{\mathrm{Rpl}}$ according to the proposed procedure and due to EDR $5^{\text {th }}$ provisions

\section{BUCKLING PARAMETERS}

To assess the buckling resistance of a pressurised spherical shell one should know all the buckling parameters $\lambda_{0}, \alpha, \beta$ and $\eta$ describing the standard capacity curve (cf. EDR $5^{\text {th }}$ and EN 1993-1-6). The dimensionless relative slenderness $\lambda$ is defined according to eqn. (5 and 6 ) and the buckling strength reduction factor $\chi$ is equal to the $p_{\mathrm{Rk}} / p_{\mathrm{Rpl}}$ ratio, where $p_{\mathrm{Rk}}$ is the characteristic value of the buckling resistance.

In order to develop a new procedure seven different modes of imperfections were considered. Detailed considerations relating to the selection and generation of these imperfection modes were presented by Błażejewski and Marcinowski [5]. Similarly as in EDR $5^{\text {th }}$ the amplitudes of imperfections were defined as follows:

$$
\Delta w_{k}=\frac{1}{Q} \sqrt{R t}
$$


where $Q$ - is the fabrication quality parameter corresponding to the specified fabrication tolerance quality. For three different fabrication quality classes $A, B$ and $C$ (excellent, high and normal) the quality parameter $Q$ adopts values 40, 25 and 16 respectively.

Taking the advantage of modified capacity curves construction of which were presented in [2], independent buckling parameters $\alpha$ and $\beta$ were determined. Analysing all obtained results and comparing them with existing proposal for cylindrical, and spherical shells (see EDR 5th) it was assumed that the $\lambda_{0}$ value is constant and equal 0.2. Parameters $\alpha$ and $\beta$ were determined from all modified capacity curves quite accurately due to the fact that they can be detected very distinctly. Calculation points describing the buckling parameter $\alpha$ were obtained from modified capacity curves determined for spherical shells of different $R / t$ ratios, different semi-angles $\varphi$ and for different imperfection modes (seven imperfection modes were considered). Amplitudes of imperfections in both compared procedures were dependent on $Q$ parameter according to relationship (7).

To guarantee the safety in all possible circumstances $\alpha$ was approximated as a lower bound of all calculation points. As a result the following function was obtained:

$$
\alpha\left(\Delta w_{k} / t\right)=\frac{0.65}{1+1.8\left(\Delta w_{k} / t\right)^{0.8}}
$$

Very similar expression describing the buckling parameter $\alpha$ exists in EDR provisions [1]:

$$
\alpha\left(\Delta w_{k} / t\right)=\frac{0,7}{1+1,9 \cdot\left(\Delta w_{k} / t\right)^{0,75}}
$$

The comparison of curves describing the buckling parameters $\alpha$ as a function of $\mathrm{R} / t$ ratio for different values of $Q$ parameter are presented in Figure 4.

The other parameter describing the final shape of the capacity curve, the $\beta$ parameter, was determined on the basis of all registered results as a weighted curve approximating points. More details regarding this stage can be found in [2]. 


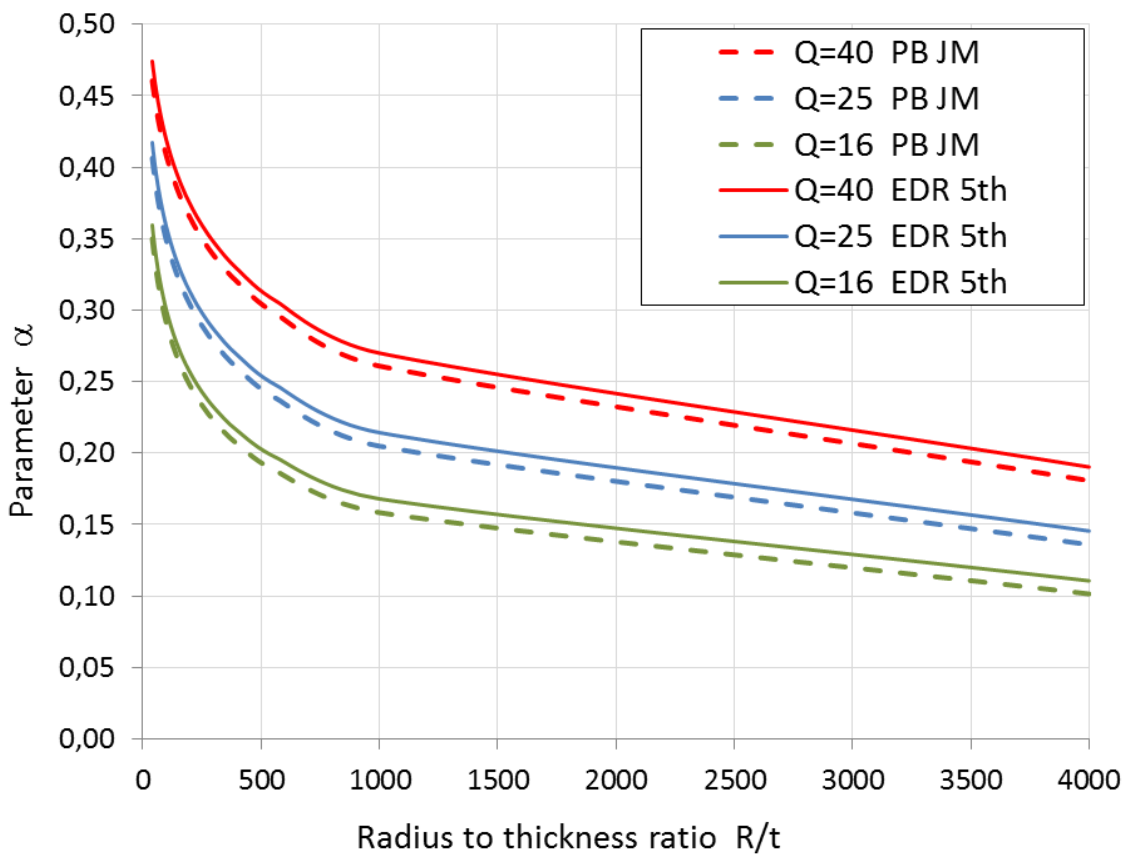

Fig. 4. Functions $\alpha(R / t)$ for different values of the $Q$ parameter

The proposed formula expressing the dependence of the $\beta$ parameter as a function of the $\Delta w_{k} / t$ ratio has the following form:

$$
\beta\left(\Delta w_{k} / t\right)=0.87\left(\frac{\Delta w_{k}}{t}\right)^{0.026}
$$

It is worth noting that both determined parameters depend not only on geometrical characteristics $R, t$, and $\varphi$ but also on fabrication quality class due to the fact that the $\Delta w_{k} / t$ ratio is expressed by $Q$. Figure 4 and 5 shows plots of $\alpha$ and $\beta$ parameters as functions of $w_{k} / t$ ratios for different values of the $Q$ parameter. In the same figure proposals of EDR $5^{\text {th }}$ were presented as well.

The comparison of presented proposals with those proposed in EDR $5^{\text {th }}$ shows that elastic buckling reduction factor $\alpha$ is smaller than its counterpart from EDR $5^{\text {th }}$. It means that the buckling strength reduction factor $\chi$ will be smaller within the elastic interval. On the other hand the greater values of the plastic range factor $\beta$ mean that the elastic-plastic range will be enlarged in comparison to the previous proposal of EDR $5^{\text {th }}$. 


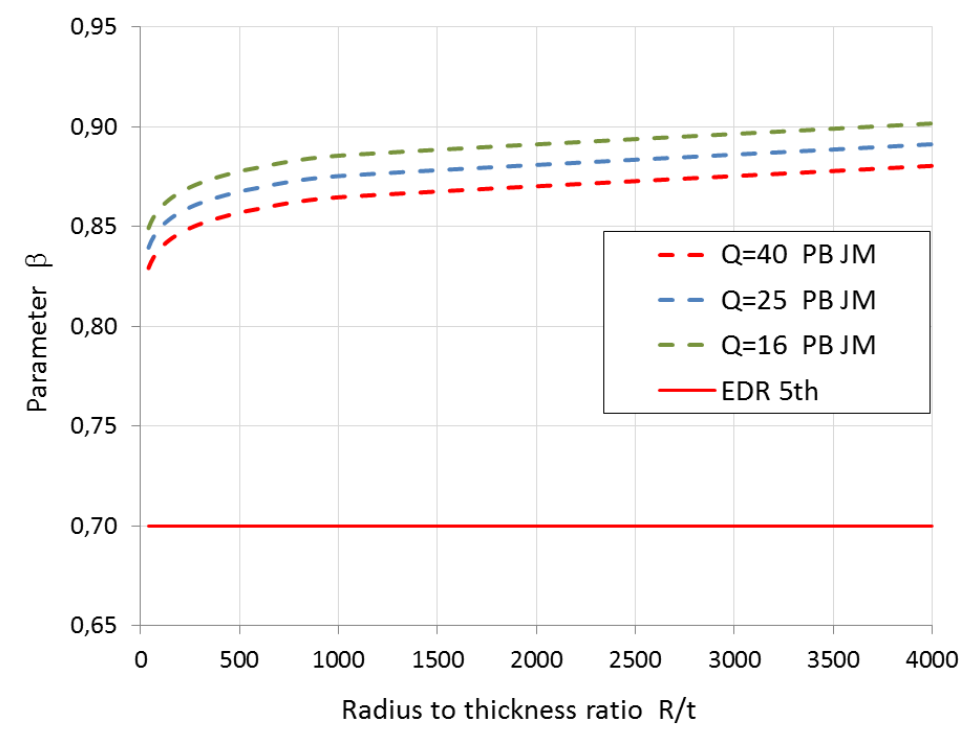

Fig. 5. Functions $\beta(R / t)$ for different values of the $Q$ parameter

\section{BUCKLING CAPACITY CURVES}

The standard form of the buckling capacity curve consistent with proposals of Schmidt [6], [7] and Rotter [8] is presented in Figure 6. The capacity curves in such a shape are recommended also in provisions of EDR [1].

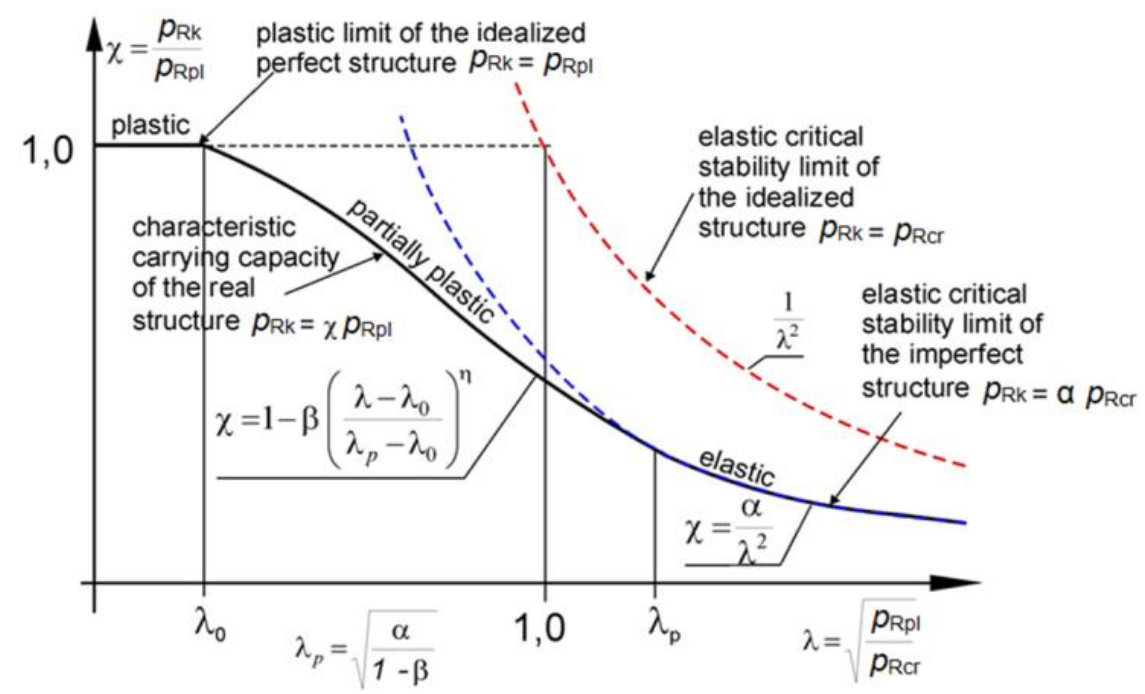

Fig. 6. The standard buckling capacity curve 
Due to some significant difficulties arising in the reference to the exact evaluation of the interaction exponent $\eta$ defining the capacity curve within the elastic-plastic range, Authors have proposed a modification of this standard capacity curve within this range. In place of the function shown in Figure 6 the polynomial of the second order was proposed, and namely

$$
\chi(\lambda)=a \lambda^{2}+b \lambda+c, \text { for } \lambda_{0} \leq \lambda \leq \lambda_{p}
$$

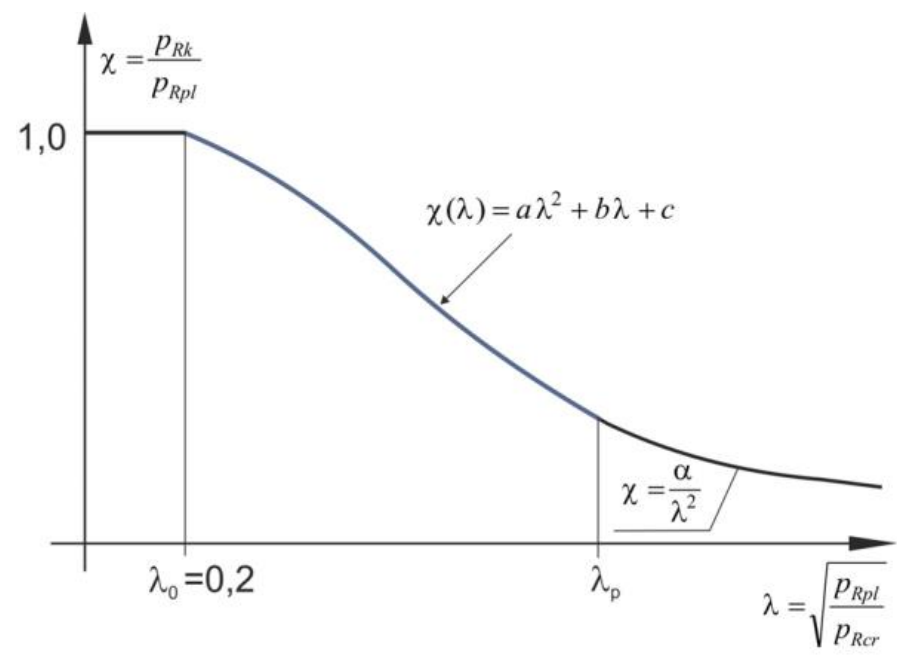

Fig. 7. The modified version of buckling capacity curve

This function was shown in Figure 7 and its coefficients were determined from continuity conditions at $\lambda_{0}$ and $\lambda_{\mathrm{p}}$ points. They adopt the following form:

$$
\begin{gathered}
a=\frac{\alpha\left(0.4-3 \lambda_{p}\right)+\lambda_{p}^{3}}{\lambda_{p}^{3}\left(0.04-0.4 \lambda_{p}+\lambda_{p}^{2}\right)}, \\
b=\frac{-2 \lambda_{p}^{4}+\alpha\left(4 \lambda_{p}^{2}-0.08\right)}{\lambda_{p}^{3}\left(0.04-0.4 \lambda_{p}+\lambda_{p}^{2}\right)}, \\
c=\frac{\alpha\left(0.12-0.8 \lambda_{p}\right)+\lambda_{p}^{4}}{\lambda_{p}^{2}\left(0.04-0.4 \lambda_{p}+\lambda_{p}^{2}\right)} .
\end{gathered}
$$

It is worth mentioning that in the existing EDR5 ${ }^{\text {th }}$ provisions the $\eta$ parameter defining $\chi(\lambda)$ in elastic-plastic range (comp. Figure 6) is constant and equals 1 . It 
means that within elastic-plastic range $\chi(\lambda)$ characteristics is linear and do not fulfils smooth continuity conditions at point of transition to the elastic range. Author's proposal is free from this drawback.

Using the approach presented above the capacity curves can be generated for the spherical shell of specific geometrical and material characteristics and for three fabrication quality classes. The example of such capacity curves were presented in Figure 8. In this figure the transition from the purely elastic range to the elasticplastic range was clearly marked.

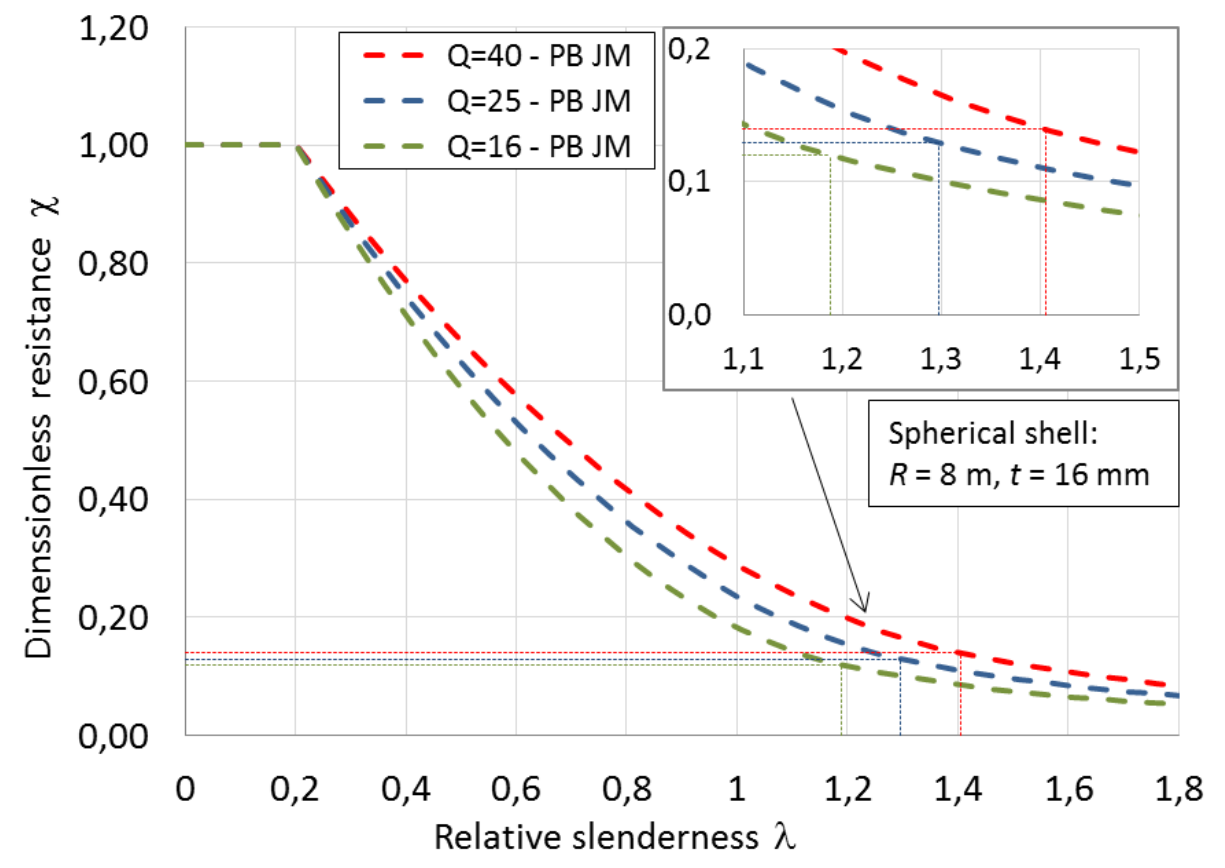

Fig. 8. Buckling capacity curves for different values of $Q$

In the proposed procedure the buckling parameter $\beta$ is variable and defined by the Formula (10). In the existing provisions of EDR $5^{\text {th }}[1]$ the buckling parameter $\beta$ is constant and equals 0,7 (comp.[1]). It means that at the point $\lambda=\lambda_{0}$ the buckling resistance parameter $\chi$ is equal 0,3 for all three fabrication quality parameters $Q$ (comp. Figure 9).

Figure 10 shows the comparison of the present proposal with existing provisions of EDR $5^{\text {th }}$. In this case capacity curves are plotted as the function of the characteristic value of the buckling resistance $p_{\mathrm{Rk}}(R / t)$. Figures 11 and 12 comprise enlargements of Figure 10 in chosen ranges. It is visible that existing provisions provide slightly lower assessment of the buckling resistance, it means that they are more conservative. 


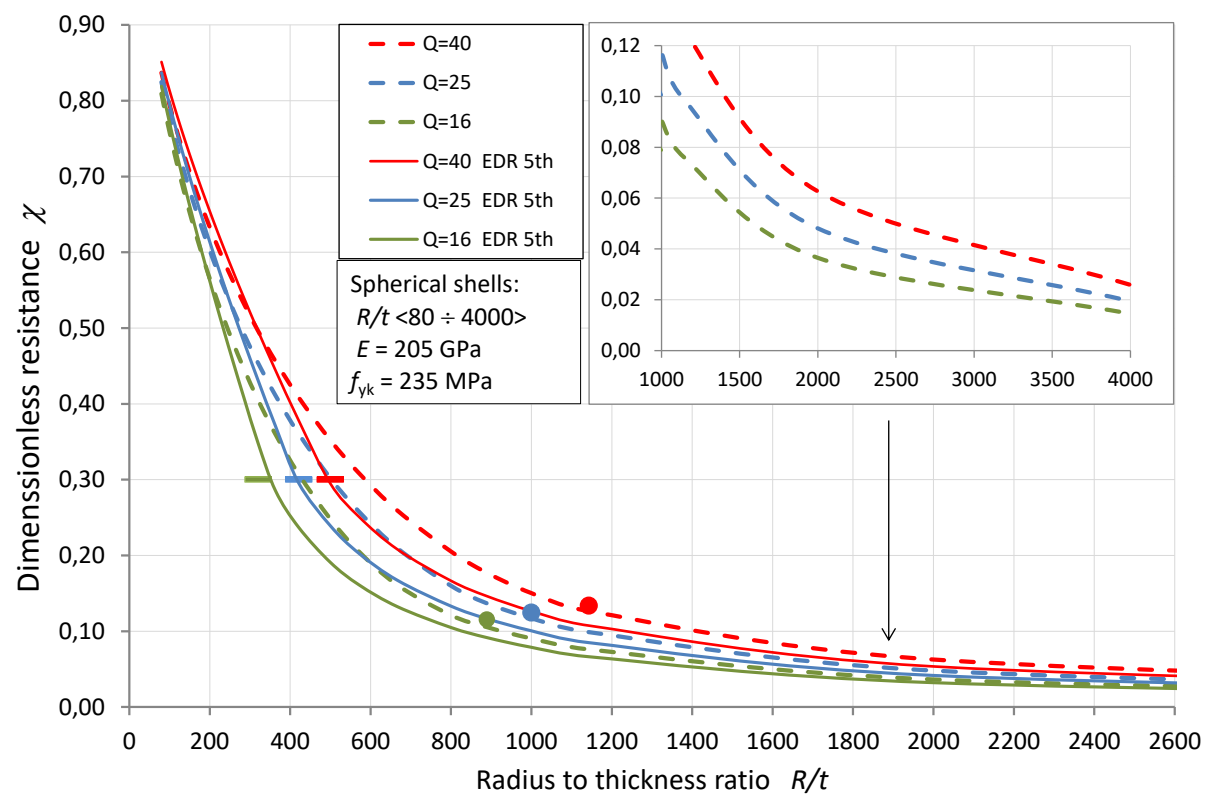

Fig. 9. Dimensionless buckling capacity $\chi$ for different parameters $Q$ according to author's proposal and due to EDR 5th

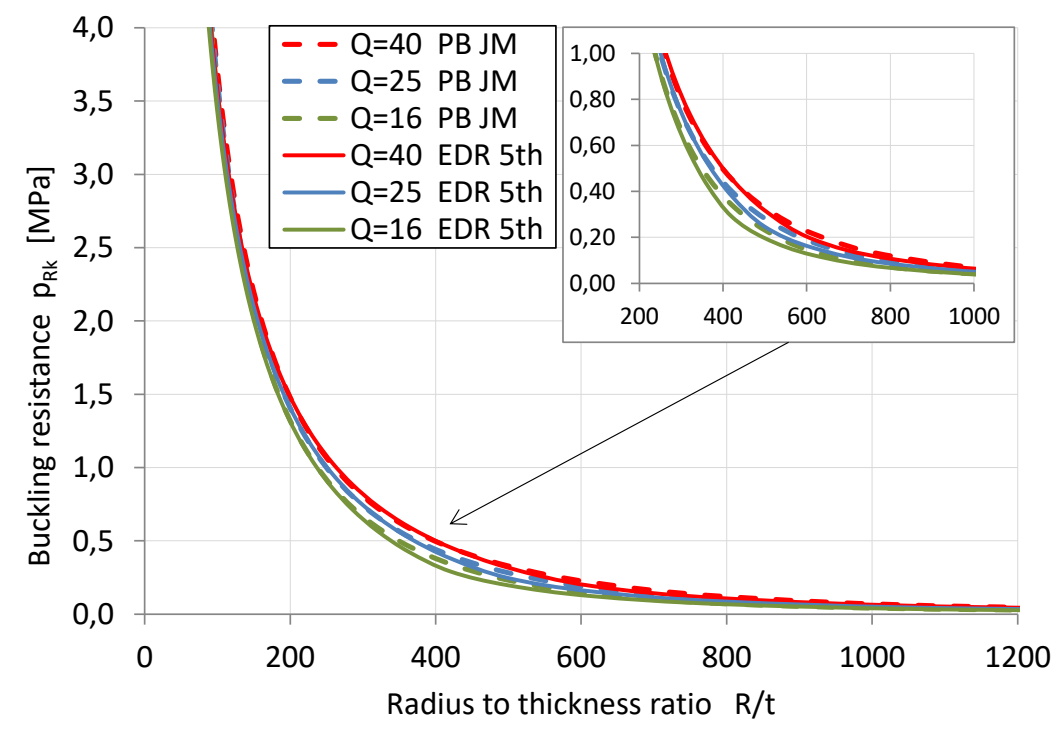

Fig. 10. The comparison with existing provisions of EDR $5^{\text {th }}$ 

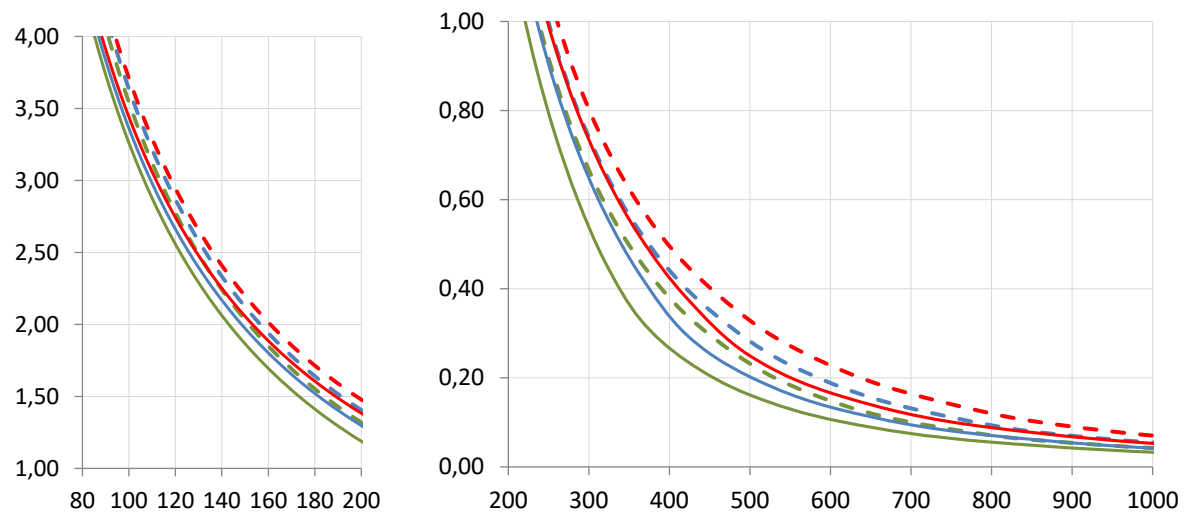

Fig. 11. Buckling capacity $p_{R k}$ as a function of $R / t$ ratio - enlargement

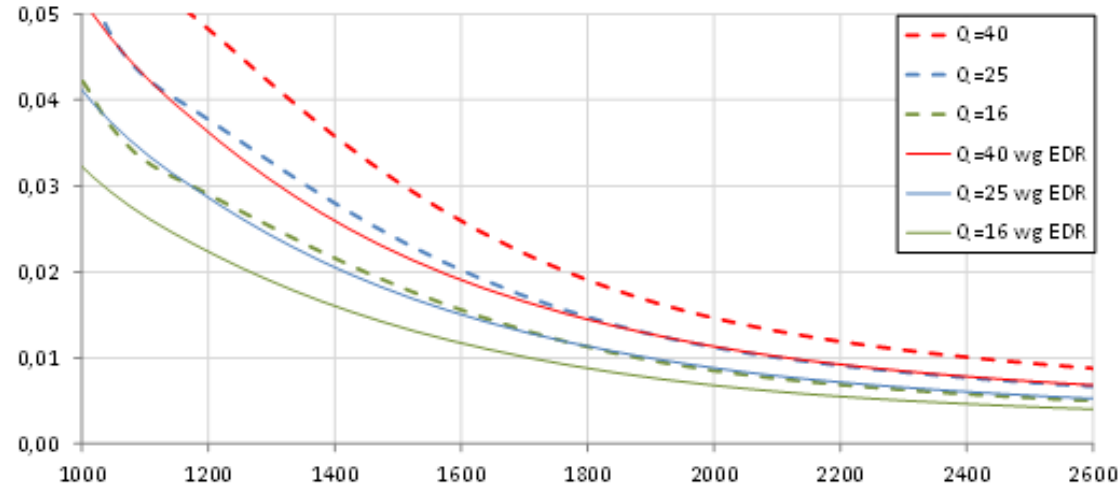

Fig. 12. Buckling capacity $p_{\mathrm{Rk}}$ as a function of $R / t$ ratio - enlargement

Analysing results presented in Figures 10 to 12 one can distinguish two intervals. Within the first interval defined by $R / t$ for $\langle 80 \div 420\rangle$, differences are smaller than $19 \%, 35 \%$ and $43 \%$ for $Q$ parameters 16,25 and 40 respectively. These differences decrease for smaller $R / t$ ratios and it is due to the fact that in both approaches all capacity curves tend to the same point $\chi=1,0$ and $\lambda=\lambda_{0}=0,2$. This fat is well visible in Figure 10.

Within the other interval defined by $R / t$ for $\langle 420 \div 560\rangle$, differences between both approaches are greater and oscillates between $35 \% \div 44 \%$. Discrepancies decrease for higher $R / t$ ratios and for $R / t=2400$ reach the values $20 \div 28 \%$ for different values of $Q$ parameter. 16, 25 and 40 respectively. 


\section{COMPARISON WITH EXPERIMENTAL RESULTS}

The procedure inserted in EDR5 ${ }^{\text {th }}$ and the procedure proposed by authors were compared with two series of experimental results. As a source of comparative analysis were chosen experiments which had comprised comparatively large number of examined specimens. The other criterion of the selection was the $R / t$ ratio of the examined shells. Experiments in which examined caps had $R / t$ ratio corresponding to $R / t$ ratio of domes encountered in engineering practice were selected to the comparative procedure.

Results of the first comparative series were published in the paper entitled: „A nonlinear theory of bending and buckling of thin elastic shallow spherical shells" was published by Abner Kaplan and Yuan-Cheng Fung in August 1954 as the Technical Note 3212 of NACA (comp. [9]). In this work not only theoretical considerations but also results of experimental results were presented.

An experimental program was carried out on a series of shallow spherical caps having a base diameter of 8 inches, nominal radii of curvature of 20 and 30 inches, and nominal thicknesses varying from 0.032 to $0.102 \mathrm{inch}$. The edges of the specimens were held between two rings which were bolted to a circular plate thus providing a clamped edge support.

The specimens were made by spinning from flat sheet. The magnesium alloy QQM-44 was selected because of its favorable ratio of yield stress to Young's modus

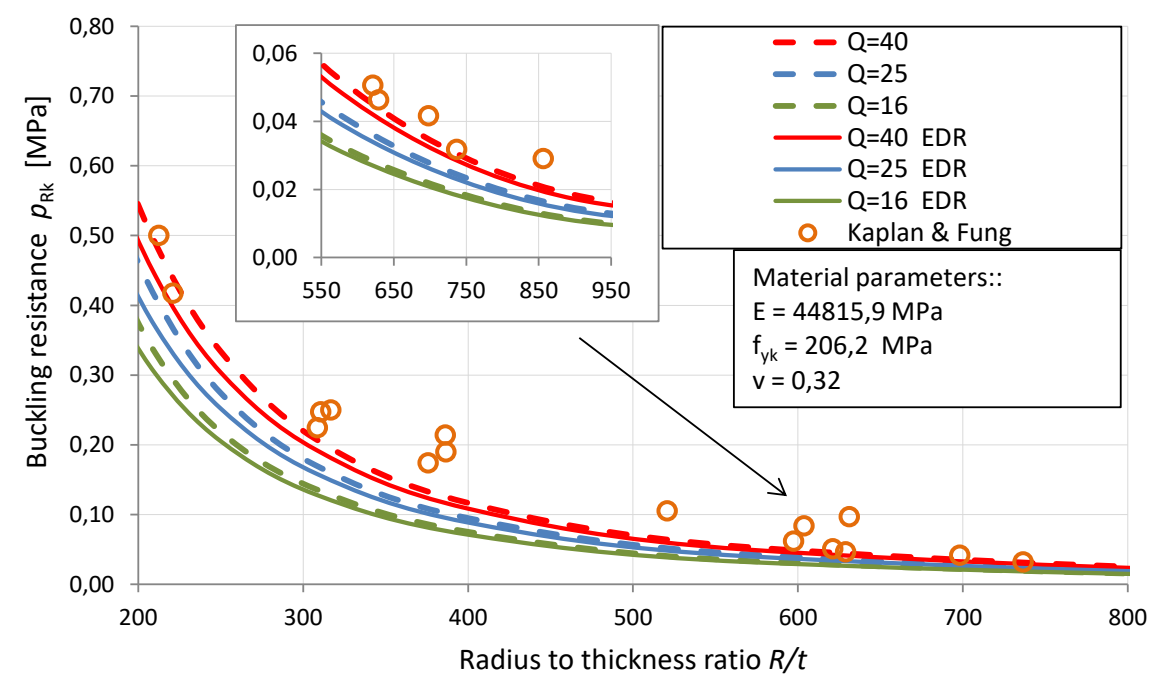

Fig. 13. Comparison of results of both procedures with experimental results of Kaplan \& Fung [9] 
us compared with other non-heat treated metals. Material parameters were as follows: Young's modulus : $E=6,5106 \mathrm{psi}=44815.92 \mathrm{MPa}$, the yield stress: $f_{\mathrm{yk}}=29900 \mathrm{psi}=206.15 \mathrm{MPa}$; Poisson's ratio $v=0.32$.

Pressure measurements were made using a Bourdon tube for pressure over $20 \mathrm{psi}$ and a mercury manometer for pressures under 20 psi. More details referring to experimental procedures can be found in [9].

Capacity curves generated for geometrical and material parameters the same as those from experiments were presented in Fig. 13. Three different fabrication quality classes defined by parameters Q (comp. [1] [2] and [3]) were taken into account. Markers in a form of circles shown in Fig. 13 refers to results obtained by Kaplan \& Fung and presented in [9]. Characteristic values of the critical pressure $p_{\text {Rk }}$ were expressed in MPa.

Looking at Fig. 13 one can observe that critical pressures obtained in experiments of Kaplan \& Fung are always above all three capacity curves proposed in [1] and [2]. It means that limits defined by capacity curves obtained by means of the new procedure are generally conservative as it should be. Curves obtained by means of the procedure inserted in EDR $5^{\text {th }}$ are even more conservative. Only in two cases experimental results are little bit lower than the capacity curve for the $Q=40$ corresponding to the best fabrication quality class. Probably in these two cases geometrical imperfections were higher than those predicted for the best admissible class defined by $\mathrm{Q}=40$.

The other series of experimental results which was the basis of comparative analysis was published in the paper entitled: „The nature of buckling in thin spherical shells" (comp. [10]). This work was the part of $\mathrm{PhD}$ thesis of Lynn Seaman. The paper included not only theoretical considerations related to buckling resistance of spherical shells but also the wide part in which results of experimental investigations were presented. Experiments were conducted on a big series of specimens counting 40 pieces.

A plastic was chosen as the shell material rather than aluminum or other light metals which have usually been used by other authors in experimental investigations. The particular plastic chosen was a polyvinyl chloride which was available in thicknesses from 0.010 inch to 0.080 inch.

The shell segments were formed from polyvinyl chloride (P.V.C.) sheets by a process known as vacuum drawing. In this method a single mold, the female, was required. The plastic sheet was heated, drawn into the mold, and allowed to cool in the new shape. Since the shells were to have five different radii - 15, 25, 35, 45 and 80 inches, five molds were manufactured from aluminium.

After forming the shells it was necessary to find the thickness and radius to which the shell actually conformed. Thicknesses were read to the nearest ten thousandth of an inch with an dial gage at five positions in the shell - one at the apex of the shell, and the other four at points halfway between the apex and the edge. An 
average of the five readings was taken as the shell thickness. The thickness variation was about $1 \%$ except for the very thin shells where variations were $10 \%$ to $12 \%$.

The radius of the spherical shell can be found if the rise in the center is known. The rise was measured to the nearest thousandth of an inch. The radius was then computed from the easy derived formula

$$
R=\frac{H^{2}+r^{2}}{2 H}
$$

where $H$ is the rise in the center, $r$ is the radius of the supported circular edge used in this measurement and $r=5.25$ inch.

All other details of the adopted measurement procedures used in conducted experiments were described in [10].

There were two basically different types of tests used. The constant volume test was the most important and it was of the controlled displacement type. A certain

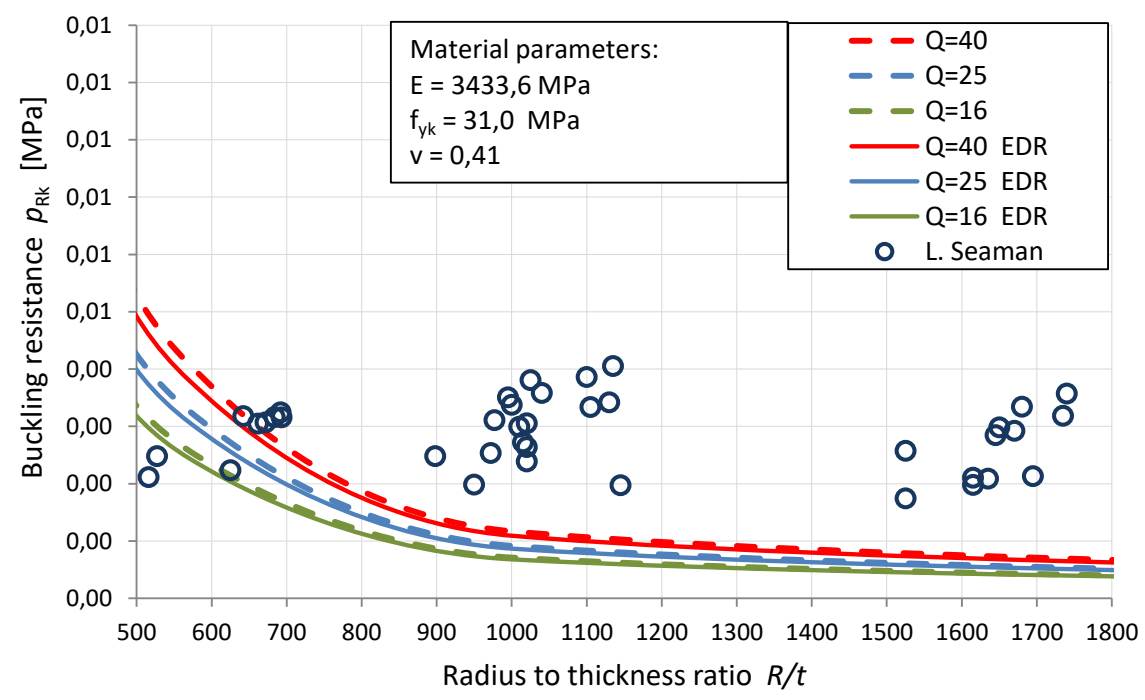

Fig. 14. Comparison of results of both procedures with experimental results of L. Seaman

strain or displacement was applied to the shell and the pressure which was required to make the shell stay in that position was read. The other type, the constant pressure test, was carried out by increasing the load until buckling occurred and hence the control was on the load, not on the displacement. 
Capacity curves generated for geometrical and material parameters the same as those from experiments were presented in Fig. 14. The following material parameters specified in [10] were used: $E=498 \cdot 10^{3} \mathrm{psi}=3433.6 \mathrm{MPa} ; f_{\mathrm{yk}}=4500$ psi $=33.0 \mathrm{MPa} ; v=0.41$. Three different fabrication quality classes defined by parameters $Q$ (comp. [1], [2] and [3]) were taken into account. Markers in a form of circles shown in Fig. 14 refers to results obtained by Seaman and presented in [10]. Characteristic values of the critical pressure $p_{\mathrm{Rk}}$ were expressed in MPa.

Looking at Fig. 14 one can observe that critical pressures obtained in experiments of Seaman are generally above all three capacity curves proposed in [1] and [2]. It means that limits defined by proposed capacity curves are generally conservative as it should be.

Also in this case curves obtained according to the procedure recommended in $\mathrm{EDR}^{\text {th }}$ have proved to be more conservative. They are located below their counterparts obtained by means of the new procedure for particular values of the fabrication quality parameter $Q$. Only in two cases experimental results are little bit lower than the capacity curve for the $Q=16$ corresponding to the worst fabrication quality class. It can be assumed that in these two cases geometrical imperfections were higher than those predicted for the worst admissible class defined by $Q=16$.

\section{RECAPITULATION}

The buckling resistance can be assessed according to the existing EDR5 ${ }^{\text {th }}$ provisions. Authors have elaborated the alternative approach (comp. [2]) which is consistent with general provisions of EN1993-1-6 [3]. The comparison of these two procedures of buckling resistance assessment of pressurised spherical shells with chosen experimental results was presented in this work. At the first step both reference quantities used in both procedures and namely $p_{R c r}$ and $p_{R p l}$ were compared. Different manners of determination of intermediate (elastic plastic range of capacity curve) segments of buckling capacity curves were compared and discussed as well. In some domains of $R / t$ ratio of analysed shells differences have reached even $40 \%$. It has proved that a comparatively big capacity reserve occurs and that the existing EDR5 ${ }^{\text {th }}$ provisions are very conservative. The comparison of author's proposal and the EDR $5^{\text {th }}$ procedure with experimental results presented in this paper shows the general correctness of both approaches. For each of them buckling capacity curves are located below points referring to experimental results. However buckling capacity curves obtained as a result of the present proposal do not manifest so huge resistance reserve. Hence it follows that the proposed procedure deserves a recommendation. 


\section{REFERENCES}

1. Rotter J. M. \& Schmidt H.: 2008. Buckling of Steel Shells. European Design Recommendations 5th Edition. ECCS.

2. Błażejewski P., Marcinowski J.: Buckling capacity curves for pressurized spherical shells. In: Recent Progress in Steel and Composite Structures: proceedings of the XIII International Conference on Metal Structures - ICMS 2016. Zielona Góra, Poland, 2016 .- London : Taylor \& Francis Group, 2016, s. $401-406$.

3. EN1993-1-6 (2006). Eurocode 3: Design of Steel Structures, Part 1.6: Strength and Stability of Shell Structures. CEN.

4. Błażejewski P., Marcinowski J.: (2013), A new approach to the buckling resistance assessment of pressurized spherical shells, SSTA: proceedings of the 10th conference. Gdańsk, Polska, 2013.- London: Taylor \& Francis Group, 2014, s. 179--182

5. Błażejewski P., Marcinowski J.: (2014), Najbardziej niekorzystne imperfekcje geometryczne stalowych powłok sferycznych, 60 Jubileuszowa Konferencja Naukowa Komitetu Inżynierii Lądowej i Wodnej PAN i Komitetu Nauki PZITB - Krynica 2014.

6. Schmidt H.: 1991 The German code DIN 18800 Part 4: Stability of shell-type steel structures, design philosophy and practical applications, International Colloquium on Buckling of Shell Structures on Land, in the Sea and in the Air, Villeurbanne, Lyon, France, 17-19 Sept., pp. 265-269.

7. Schmidt H.: 1994 Stability of shells, CEN TC250 SC3 PT 3 (Masts, Chimneys, Pipelines) Report, August, 12 pp.

8. Rotter J. M.: 2002 Shell Buckling and Collapse Analysis for Structural Design: The New Framework of the European Standard, in New Approaches to Structural Mechanics, Shells and Biological Structures, eds H.R. Drew and S. Pellegrino, Kluwer Academic Publishers, London, pp. 355-378.

9. Kaplan A. \& Fung Y. C.: (1954), A nonlinear theory of bending and buckling of thin elastic shallow spherical shells. U. S. N. A. C. A. Technical Note 3112.

10. Seaman L.: (1962), The Nature of Buckling in Thin Spherical Shells. Watertown Arsenal Laboratories, Monograph Series No 46.

11. COSMOS/M, Finite Element Analysis System, Version 2.5, Structural Research and Analysis Corporation, Los Angeles, California, 1999. 


\section{PORÓWNANIE KRZYWYCH NOŚNOŚCI WYBOCZENIOWEJ POWŁOK SFERYCZNYCH OBCIĄŻONYCH CIŚNIENIEM Z ZALECENIAMI EDR ORAZ Z WYNIKAMI BADAŃ EKSPERYMENTALNYCH}

\section{Streszczenie}

W niniejszej pracy przedstawiono porównanie dwóch procedur szacowania nośności wyboczeniowej powłok sferycznych na tle wybranych wyników badań eksperymentalnych. Porównanie głównych wartości referencyjnych występujących w obu procedurach oraz porównanie sposobu wyznaczania odcinka sprężystoplastycznego krzywej nośności wyboczeniowej dokładnie pokazuje i tłumaczy różnice pomiędzy dwoma algorytmami obliczeniowymi. W pewnych zakresach wartości stosunku R/t dla konkretnych przypadków, różnice te sięgają nawet $40 \%$. Świadczy to o dość dużym zapasie nośności i konserwatywnym charakterze zapisów zawartych w EDR5th. Porównanie dwóch procedur obliczeniowych $\mathrm{z}$ wynikami badań eksperymentalnych pokazuje zasadność stosowania obu podejść. Dla każdego z nich otrzymane przebiegi krzywych nośności wyboczeniowej znajdują się poniżej punktów odpowiadających wynikom eksperymentalnym. Jednakże krzywe nośności otrzymane wg nowej procedury wykazują większą zbieżność $\mathrm{z}$ wynikami badań eksperymentalnych. Stąd wniosek, że stosowanie bardziej zachowawczych metod obliczeniowych można uznać za niezasadne.

Słowa kluczowe: powłoka sferyczna, nośność wyboczeniowa, MES, analizy numeryczne, krzywe nośności wyboczeniowej

Editor received the manuscript: 28.06.2016 